\title{
A Study on Etiological Evaluation of Children Aged 2 Months-12 Years with status epilepticus Admitted in a Tertiary Care Centre
}

\author{
Saheli Dasgupta ${ }^{1}$, Suparna Guha², Asha Mukherjee ${ }^{3}$ \\ ${ }^{1}$ Postgraduate Trainee, Department of Paediatrics, Vivekananda Institute of Medical Sciences, \\ Kolkata, West Bengal, India. \\ ${ }^{2}$ Associate Professor, Department of Paediatrics, Vivekananda Institute of Medical Sciences, \\ Kolkata, West Bengal, India. \\ ${ }^{3}$ Professor, Department of Paediatrics, Vivekananda Institute of Medical Sciences, \\ Kolkata, West Bengal, India.
}

\section{ABSTRACT}

\section{BACKGROUND}

Status epilepticus is a medical emergency requiring early and effective treatment. The most important cause of status epilepticus varies with age of the child. While febrile seizure with S.E. are the most common cause in children less than 5 years, infections and trauma are more common in older children. The important risk factors for status epilepticus are a history of epilepsy, younger age of the patient, genetic predisposition and acquired brain insult. Airway, respiratory, and circulatory support should be provided immediately. Initial investigations should then focus on possible metabolic derangements and conditions that require immediate treatment, such as meningitis. The recommended first-line therapy includes a fast-acting benzodiazepine followed by longer-acting antiepileptic. In cases of refractory status epilepticus, further treatment will depend on the setting. When paediatric intensive care is available, midazolam, barbiturates, and propofol are options. Neuroimaging by either CT or MRI should be undertaken only after the patient has been stabilized and the convulsive seizure activity controlled.

\section{METHODS}

The study was conducted among children aged 2 months to 12 years of age admitted to Vivekananda Institute of Medical Sciences, Kolkata for 1 year. Ethical clearance was obtained from the institute's ethics committee before enrolment. Both newly diagnosed patients and known cases of seizure disorder presenting with status epilepticus were enrolled. 50 Children aged 2 months to 12 years presenting with status epilepticus were selected.

\section{RESULTS}

50 patients were studied. Mean age was 3.12 (Range 2 months- 12 years). Male to female ratio is $1.3: 1.74 \%$ children had GTCS (generalized tonic clonic seizure), focal seizures were seen in $18 \%$ and non-convulsive status epilepticus was seen in $2 \%$. The most common cause was found to be febrile seizure with status epilepticus which was $76 \% .14 \%$ patients had structural lesions found in MRI. 4\% cases were found to have ADEM (Acute Disseminated Encephalo-Myelitis). 6\% cases were found to have diffuse slowing on EEG and 8 \% showed bilateral epileptiform discharges on EEG.

\section{CONCLUSIONS}

Status epilepticus is a common neurological emergency in children. The mortality and morbidity associated with SE has decreased over the years due to a systematic approach and prompt management. Earlier, duration of status epilepticus was 30 minutes as per definition. Pathologically, however, hippocampal neurons begin to die after 30 minutes of sustained seizure activity. So, using operational definition of 5 mins., is helpful as it prevents brain damage. This was the reason for using the operational definition of 5 mins., in our study.

\section{KEY WORDS}

Status Epilepticus, Children, Aetiology
Corresponding Author:

Saheli Dasgupta,

Vivekananda Institute of Medical Sciences, \#99 Sarat Bose Road,

Kolkata-700026, West Bengal, India.

E-mail: 1988saheli@gmail.com

DOI: $10.14260 /$ jemds/2019/555

Financial or Other Competing Interests: None.

How to Cite This Article:

Dasgupta S, Guha S, Mukherjee A. A study on etiological evaluation of children aged 2 months-12 years with status epilepticus admitted in a tertiary care centre. J. Evolution Med. Dent. Sci. 2019;8(32): 25492553, DOI: $10.14260 /$ jemds/2019/555

Submission 08-02-2019,

Peer Review 25-07-2019,

Acceptance 01-08-2019,

Published 12-08-2019. 


\section{BACKGROUND}

Status epilepticus is defined as a seizure lasting more than 30 minutes or recurrent seizures for more than 30 minutes during which the patient does not regain consciousness. Generalized, convulsive status epilepticus refers to more than 5 min of (i) continuous seizures or (ii) two or more discrete seizures between which there is incomplete recovery of consciousness. Pathologically, however, hippocampal neurons begin to die after 30 minutes of sustained seizure activity. ${ }^{1}$ the limitation of this definition thus suggests that treatment should not be initiated until pathological damage has already been demonstrated. Newer operational definitions have suggested that seizures lasting longer than 5 minutes are unlikely to discontinue spontaneously and should be treated. ${ }^{2}$ this is a more useful definition since treatment for SE is not delayed. In addition, individual unprovoked seizures can on occasion be observed and may not warrant aggressive treatment. In our study duration of SE has been taken as 5 minutes. We wanted to determine the aetiology and epidemiology of status epilepticus in 2-months-old infants to 12-years-old children and assess the neuroimaging.

\section{METHODS}

The study started with taking ethical committee clearance from the institution followed by proper selection of infants of 2 months to 12 years old children who fitted in the operational definition of status epilepticus. Consents from parents of the children enrolled were taken. After initial management investigations sent were blood glucose, blood gas analysis haematological, biochemical and microbiological study of blood (Urine and CSF where needed), brain imaging (MRI brain, CT scan) Electroencephalogram (EEG).

\section{Place of Study}

Department of Paediatrics Medicine, Vivekananda Institute of Medical Sciences, Ramakrishna Mission Seva Pratish than, Kolkata 26.

\section{Duration of Study}

1 year

\section{Study Design}

Descriptive study.

\section{Study Population}

2 months old infants- 12 year's old children admitted with status epilepticus in our institution.

\section{Sample Size}

50

\section{Inclusion Criteria}

1. Age more than 2 months up to 12 years old children.

2. More than 5 minutes of continuous seizure or two discrete seizure with incomplete recovery of consciousness.

\section{Exclusion Criteria}

1. Pseudoseizure or seizure mimickers.

2. Children with head trauma.

3. Poisoning.

\section{RESULTS}

\begin{tabular}{|c|c|c|}
\hline Age Group (in Years) & Number & $\mathbf{\%}$ \\
\hline$<\mathbf{1}$ & 4 & $8.0 \%$ \\
\hline $1-5$ & 35 & $70.0 \%$ \\
\hline $6-10$ & 11 & $\mathbf{1 0 0 . 0} \%$ \\
\hline Total & $\mathbf{5 0}$ & \\
\hline \multicolumn{2}{|c|}{ Table 1. Age Distribution of the Patients } \\
\hline $\begin{array}{l}\text { The mean age (mean } \pm \text { S.D..) of the patients was 3.81 } \pm 2.49 \text { years with range } 0.50- \\
10.00 \text { years and the median age was 3.20 years. Thus, status epilepticus was more } \\
\text { prevalent in the age 1-5 years followed by 6-10 years. }\end{array}$ \\
\hline
\end{tabular}

\begin{tabular}{|c|c|c|}
\hline Gender & Number & $\mathbf{\%}$ \\
\hline Male & 28 & $56.0 \%$ \\
\hline Female & 22 & $44.0 \%$ \\
\hline Total & 50 & $100.0 \%$ \\
\hline Male: Female & $1.3: 1.0$ & \\
\hline \multicolumn{2}{|c|}{ Table 2. Gender Distribution of the Patients } \\
\hline $\begin{array}{l}\text { Proportion of males (56.0\%) was higher than that of females (44.0\%).The ratio of } \\
\text { Male: Female was 1.3:1.0. Thus, status epilepticus was more prevalent among } \\
\text { males. }\end{array}$ \\
\hline
\end{tabular}

\begin{tabular}{|c|c|c|}
\hline Chief Complaints & Number & $\%$ \\
\hline Fever with convulsion & 38 & $76.0 \%$ \\
\hline Unprovoked convulsion & 7 & $14.0 \%$ \\
\hline Fever with convulsion with altered consciousness & 2 & $4.0 \%$ \\
\hline Repeated fall with loss of consciousness & 1 & $2.0 \%$ \\
\hline Twitching of eyes with focal seizure with altered sensorium & 1 & $2.0 \%$ \\
\hline Unprovoked seizures with unable to move right hand and leg & 1 & $2.0 \%$ \\
\hline Total & $\mathbf{5 0}$ & $100.0 \%$ \\
\hline \multicolumn{3}{|c|}{ Table 3. Distribution According to Chief Complaints of the Patients } \\
\hline \multicolumn{3}{|c|}{$\begin{array}{l}\text { Fever with seizures }(76.0 \%) \text { was significantly more prevalent among the chief } \\
\text { complaints followed by unprovoked seizures }(14.0 \%) \text {. All other complaints were } \\
\text { more or less equally distributed. }\end{array}$} \\
\hline
\end{tabular}

\begin{tabular}{|c|c|c|}
\hline Type of Seizure & Number & $\mathbf{\%}$ \\
\hline GTCS & 37 & $74.0 \%$ \\
\hline Focal & 9 & $18.0 \%$ \\
\hline Focal with secondary generalization & 3 & $6.0 \%$ \\
\hline NCSE & 1 & $2.0 \%$ \\
\hline Total & $\mathbf{5 0}$ & $\mathbf{1 0 0 . 0} \%$ \\
\hline
\end{tabular}

Table 4. Distribution According to Type of Seizure of the Patients

Among the types of seizure GTCS (74.0\%) was significant most common followed by focal (18.0\%). Only 1 case of NCSE was found.

\begin{tabular}{|c|c|c|}
\hline Duration of Seizure (in Minute) & Number & $\mathbf{\%}$ \\
\hline$<10$ & 18 & $36.0 \%$ \\
\hline $10-19$ & 20 & $40.0 \%$ \\
\hline $20-29$ & 8 & $16.0 \%$ \\
\hline $30-35$ & 4 & $8.0 \%$ \\
\hline Total & $\mathbf{5 0}$ & $\mathbf{1 0 0 . 0 \%}$ \\
\hline
\end{tabular}

Table 5. Distribution According to Duration of Seizure

The mean ( \pm s.d.) duration of seizure $13.76 \pm 8.05$ minutes with range 6 - 35 minutes and the median was 10 minutes. Most of the duration was within 20 minutes $(76.0 \%)$.

\begin{tabular}{|c|c|c|}
\hline Family History of Seizure & Number & $\%$ \\
\hline Present & 7 & $14.0 \%$ \\
\hline Absent & 43 & $86.0 \%$ \\
\hline Total & 50 & $100.0 \%$ \\
\hline \multicolumn{3}{|c|}{$\begin{array}{l}\text { Table 6. Distribution According to Family History of } \\
\text { Seizure of the Patients }\end{array}$} \\
\hline
\end{tabular}

\begin{tabular}{|c|c|c|}
\hline MRI Brain & Number & $\mathbf{\%}$ \\
\hline Encephalitis & 6 & $12.0 \%$ \\
\hline Periventricular leucomalacia & 5 & $10.0 \%$ \\
\hline Neurocysticercosis & 3 & $6.0 \%$ \\
\hline Acute disseminated encephalomyelitis & 2 & $4.0 \%$ \\
\hline Dysembryoplastic neuroepithelial tumour & 1 & $2.0 \%$ \\
\hline Lissencephaly with DWM & 1 & $2.0 \%$ \\
\hline Porencephaly & 1 & $2.0 \%$ \\
\hline
\end{tabular}




\begin{tabular}{|c|c|c|}
\hline Tuberculoma & 1 & $2.0 \%$ \\
\hline Tuberous sclerosis & 1 & $2.0 \%$ \\
\hline Normal & 29 & $58.0 \%$ \\
\hline Total & $\mathbf{5 0}$ & $\mathbf{1 0 0 . 0 \%}$ \\
\hline
\end{tabular}

Table 7. Distribution Findings of MRI Brain of the Patients

As per MRI brain $58.0 \%$ of the cases were having normal findings. $42 \%$ had abnormal MRI findings. Among abnormal findings Encephalitis (12.0\%) was most common followed by Periventricular leucomalacia $(10.0 \%)$

\begin{tabular}{|c|c|c|}
\hline EEG & Number & $\mathbf{\%}$ \\
\hline Bitemporal epileptiform discharges & 2 & $4.0 \%$ \\
\hline Diffuse slowing & 3 & $6.0 \%$ \\
\hline Diffuse slowing with seizure activity & 2 & $4.0 \%$ \\
\hline Epileptiform discharges & 4 & $8.0 \%$ \\
\hline Focal discharge & 1 & $2.0 \%$ \\
\hline Generalized seizure disorder & 1 & $2.0 \%$ \\
\hline Generalized slowing & 1 & $2.0 \%$ \\
\hline Paroxysmal dysrhythmia & 1 & $2.0 \%$ \\
\hline Seizure disorder & 1 & $2.0 \%$ \\
\hline Normal & 34 & $68.0 \%$ \\
\hline Total & $\mathbf{5 0}$ & $\mathbf{1 0 0 . 0} \%$ \\
\hline
\end{tabular}

Table 8. Distribution Findings of EEG of the Patients

As per EEG $68.0 \%$ of the cases were having normal findings. 32\% had abnormal EEG findings. Among abnormal findings Epileptiform discharges (8.0\%) was most common followed by Diffuse slowing $(6.0 \%)$.

\begin{tabular}{|c|c|c|}
\hline CSF Abnormality (Cytological, Biochemical) & Number & $\%$ \\
\hline Abnormal & 5 & $10.0 \%$ \\
\hline Normal & 5 & $10.0 \%$ \\
\hline Not Done & 40 & $80.0 \%$ \\
\hline $\begin{array}{c}\text { Total } \\
\end{array}$ & $\mathbf{5 0}$ & $100.0 \%$ \\
\hline \multicolumn{3}{|c|}{$\begin{array}{c}\text { Table 9. Distribution of Findings of CSF Abnormality (Cytological, } \\
\text { Biochemical) of the Patients }\end{array}$} \\
\hline
\end{tabular}

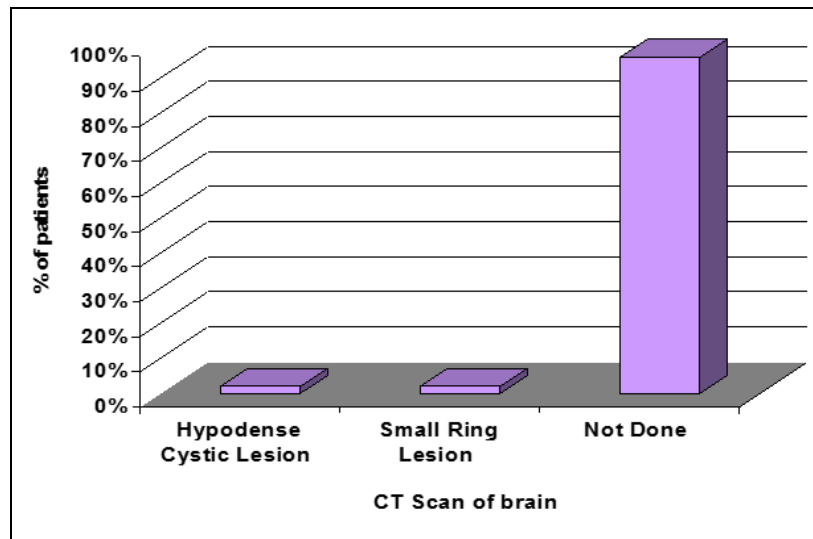

Figure 2. Distribution Findings of CT Scan Brain of the Patients

As per CT Scan 1(2.0\%) had Hypodense Cystic Lesion and another patient 1(2.0\%) had Small Ring Lesion. CT Scan was not done for $48(96.0 \%)$ patients.

\section{Distribution of CSF for JE Antibody of the Patients}

As per CSF for JE antibody findings $3(6.0 \%)$ patients had negative CSF and $2(4.0 \%)$ had positive CSF. CSF for JE Antibody was not done for 45 (90.0\%) patients.

\section{Distribution of CSF Antibodies to HSV of the Patients}

As per CSF antibodies to HSV 2(4.0\%) patients had negative findings and $3(6.0 \%)$ had positive findings. CSF antibodies to HSV was not done for $45(90.0 \%)$ patients.

\section{DISCUSSION}

Status epilepticus (SE) is a life-threatening emergency that requires prompt recognition and management. Immediate treatment of status epilepticus is crucial to prevent adverse neurologic and systemic consequences.

The incidence of status epilepticus in our study was found to be 6.6 per 1000 paediatric patients admitted in our institution. In our study male female ratio was found to be 1.3:1 (Table 1). Murthy et al, in their study found that male to female ratio was 1.3:1. ${ }^{3}$ In a study conducted by Kumar M, Kumari R, Narain N it was found to be 1.5:1. ${ }^{4}$ There is a strong effect of age on the frequency and aetiology of SE, as well as on the type of child who has SE. In our study it was found to be $8 \%$ in less than 1 -year age, $70 \%$ in the age group 1-5 years, $22 \%$ in the age group 6-10 years. Thus, status epilepticus was more prevalent in the age 1-5 years followed by 6-10 years (Table 2).In a study conducted by Gulati et al it was seen that $56 \%$ patients were less than 2 years 5 . The reason for this predominance of SE in younger children is not known. Probably, mechanisms for control of seizure activity are fragile in younger children and may get disrupted with minimal abnormalities in neuro function. The most common type of status epilepticus was found to be generalized tonic clonic convulsion (GTCS). In our study it was found that GTCS was most common (74\%) followed by focal (18\%).In $2 \%$ cases non convulsive status epilepticus(NCSE) was found (Table 4). In a study conducted by Kumar M, Kumari R, Narain N, GTCS was observed in $91.4 \%$ of SE patients while $8.6 \%$ had partial SE. 4

Paediatric SE is divided into three categories: initial SE (20-30 min), established SE (30-60 min) and refractory SE ( $>60 \mathrm{~min}$ ). In our study it was found that in $36 \%$ cases duration was less than 10 mins, in $56 \%$ it was $10-30$ mins, while in $8 \%$ cases it was more than 30 mins., (Table 5). In a study conducted by Saz EU, Karapinar B, it was observed that in $30 \%$ of the children episodes lasted for $20-30$ mins., in $37 \%$ the duration was between 30-60 mins., while 33\% had refractory $\mathrm{SE}^{6}$. In a study conducted by Jeffrey Bucchalter it was found that $24 \%$ had a mean seizure duration of 31 minutes. ${ }^{7}$ In our study it was found that fever was the most common symptom and was found in $72 \%$ children, unprovoked seizures was found in $14 \%$ cases(Table 3 ).

In the study conducted by Kumar M, Kumari R, Narain N, it was found that fever was the most common symptom associated with patients of SE and it was seen in 57 patients (67.14\%). In our study $16 \%$ cases had a previous history of convulsion while $84 \%$ presented with SE as first episode of convulsion. In the study by Kumar M, Kumari R, Narain N, $25.7 \%$ had prior history of convulsion whereas $74.3 \%$ presented with SE as first episode of convulsion. ${ }^{4}$

Our study showed that only $14 \%$ had a family history of seizure (Table 6). In a study conducted by M Wipopo EE, Akhatar S, Fan P in Zhongnan hospital, China it was seen that family history of seizure was noted in only $9.5 \%$ patients. ${ }^{8}$ In a study conducted by Singh RK, Stephens S, Berl MM, Chang T it was found $25 \%$ had a family history of seizure. ${ }^{9}$ Shinnar $\mathrm{S}$, Pellock JM, Berg AT, O'Dell C found in their study 11\% had a family history of epilepsy while $15 \%$ had a family history of febrile seizures. ${ }^{10}$

In our study $28 \%$ of patients with status epilepticus were admitted in PICU. No mortality was seen in our study. Lacroix J, Deal C, Gauthier M studied admission of children with status epilepticus in paediatric intensive care unit (PICU) over $10 \mathrm{yrs}$ and showed that 147 children 0 to 16 yrs., of age (median 1; mean $3.4+/-3.9$ [SD])with status epilepticus were admitted to a PICU.11

Neuroimaging can identify structural causes for SE, especially to exclude the need for neurosurgical intervention in children with new-onset SE without a prior history of epilepsy, or in those with persistent SE despite appropriate 
treatment. It should only be done after the child is appropriately stabilized and the seizure activity controlled. Neuroimaging largely has been used retrospectively in paediatric neurovirology upon laboratory confirmation of disease. MRI remains one of the most sensitive tests for diagnosing encephalitis in children. MRI brain is more sensitive and specific than CT scanning. In our study $42 \%$ had abnormal MRI brain findings. The most common findings was encephalitis (12\%) followed by periventricular leucomalacia (10\%), neurocysticercosis in $6 \%$ cases, acute disseminated encephalomyelitis(ADEM) in 4\% cases, porencephaly in $2 \%$, tuberculoma in $2 \%$, tuberous sclerosis in $2 \%$, lissencephaly with dandy walker malformation in $2 \%$ child, dysembryoplastic neuroepithelial tumour in $2 \%$ cases(Table 7).

A meta-analysis reported structural lesions in $7.8 \%$ of childhood SE, commonly CNS malformations, trauma, and stroke/haemorrhage. In a more recent study ${ }^{12}$, the yield of MRI to detect structural lesions in convulsive SE was 31\%. In the Indian setting, where inflammatory granulomas are a common cause of seizures ${ }^{13}$, neuroimaging is likely to provide a higher yield.

Lyons TW, Johnson KB, Michaelson KA in their study showed that $36 \%$ cases had abnormalities on neuroimaging (Non-contrast CT scan and Magnetic resonance imaging) ${ }^{14}$. In a study conducted by Yoong M, Madari R, Martinos M it was found that abnormalities on brain MRI in $31.3 \%$ of children with convulsive status epilepticus (CSE). ${ }^{14}$ Singh RK, Stephens S, Berl MM showed in their study that $20 \%$ of brain CTs and $58 \%$ of brain MRIs were abnormal in paediatric SE, with neuroimaging altering acute management in $24 \%$ of patients ${ }^{15}$. Keros S, Department of paediatric neurology, Weill Cornell medical college showed in his study that MRI abnormalities were noted in approximately $23 \%$ of study patients ${ }^{16}$. In our study $32 \%$ cases had abnormal findings in EEG. Bilateral epileptiform discharges were the most common finding $(8 \%)$ followed by diffuse slowing (6\%).Generalized slowing was found in 2\% cases (Table 8). Nordli DR Jr, Moshé SL, Shinnar $S$ showed in their FEBSTAT study electroencephalogram(EEGs) was abnormal in $45.2 \%$ with the most common abnormality being focal slowing; these were maximal over the temporal areas in almost all cases ${ }^{17}$.

19 paediatric patients with NCSE from the epilepsy database of the Comprehensive Epilepsy Center at, Columbia University were studied by Tay SK, Hirsch LJ, Leary L and it was found that six patients had associated periodic lateralized epileptiform discharges (PLEDs), one had generalized periodic epileptiform discharges (GPEDs). ${ }^{18}$ Singh RK, Stephens S, Berl MM showed in their study out of 139 patients $40 \%$ had normal EEGs; $19 \%$ showed focal epileptiform activity, 6\% showed focal slowing, 9\% showed generalized slowing. ${ }^{19}$ In a study conducted by Riviello et al EEG findings were abnormal in $43 \%$ cases. ${ }^{20}$ In our study among paediatric status epilepticus $4 \%$ cases had neurocysticercosis. Among them $2 \%$ had hypodense cystic lesion in NCCT while another $2 \%$ had small ring lesion (Figure 2).

Bhattacharjee S, Biswas P, Mondal T in their study showed about paediatric neurocysticercosis in 38 cases in Eastern India. Overall patients presented with generalized seizure in $55.3 \%$, focal in $31.6 \%$, headache \pm vomiting in $63.2 \%$, focal neuro-deficit in $10.5 \%$ and combination of symptoms in $60.5 \%$ cases. Contrast CT brain showed a solitary lesion in 27 (71.1\%) and multiple in the rest. ${ }^{21}$

In our study cerebrospinal fluid examination was done in $20 \%$ children. Among them $10 \%$ children showed meningitis of which $5 \%$ are of bacterial meningitis. Remaining $5 \%$ showed viral meningitis. CSF for Japanese encephalitis (JE) antibody was found in $4 \%$ patients. CSF for herpes simplex virus (HSV) antibodies was found in 6\% cases (Table 9) Our study was comparable to that found by Sadarangani M, Seaton C, Scott JA in Kenya which showed that $9 \%$ had acute bacterial meningitis. ${ }^{22}$ Similarly, in another study conducted by Bleck TP it was seen central nervous system (CNS) infection was seen in $11 \%$ cases. $^{23}$ Bucchalter J in his study showed that the most common acute symptomatic cause was CNS infection (9\%). Smith DM, McGinnis EL, Walleigh DJ, Abend NS in their study 'Management of status epilepticus in children' showed that CNS infections was found in $3 \%$ cases. $^{24}$

In our study the first line antiepileptics used were lorazepam. The second line antiepileptics used were fosphenytoin and levetiracetam. $66 \%$ patients were treated with lorazepam intravenous. $24 \%$ patients required lorazepam and fosphenytoin to control the convulsion. in $6 \%$ cases levetiracetam was used. Devendra Mishra, Suvasini Sharma, Naveen Sankhyan in their study Consensus Guidelines on Management of Childhood Convulsive status epilepticus discussed about the pharmacotherapy of status epilepticus in children. Benzodiazepines are first line drugs for treatment of SE in children. The choice within the benzodiazepines is based on side-effects and pharmacokinetic properties. Several RCTs and systematic reviews have concluded that lorazepam is the agent of choice among the benzodiazepines. ${ }^{25,26}$ Children receiving lorazepam are less likely to require additional doses of anticonvulsants to stop seizures, develop respiratory depression, and require admission to intensive care unit. If lorazepam is not available, midazolam or diazepam can be used for aborting the seizure. Overall, 26 RCTs (Two class I27,28 and 24 class III ${ }^{29}$ ) examined efficacy of initial therapy. In 25 of these RCTs, benzodiazepines were one or both of the study medications (Two class I studies and 23 class III studies). In one class I trial 93, 273 children (aged 3 months to 18 years) were enrolled and randomized to either diazepam $0.2 \mathrm{mg} / \mathrm{kg}$ (Maximum dose $8 \mathrm{mg}$ ) or lorazepam $0.1 \mathrm{mg} / \mathrm{kg}$ (maximum dose $4 \mathrm{mg}$ ). If seizures continued after 5 more minutes, then half of the initial study drug dose could be repeated. If seizures continued another 7 more minutes, then fosphenytoin was given.

After using short-acting benzodiazepines, phenytoin is one of the preferred second line anticonvulsant ${ }^{30}$. Fosphenytoin is a water-soluble pro-drug of phenytoin which is preferred over phenytoin. In contrast to phenytoin, there were no Fosphenytoin-related significant cardiac arrhythmias, change in heart rate, respiration or blood pressure. Fosphenytoin/phenytoin is generally preferred over phenobarbital because it is less likely to cause respiratory depression and alter the level of consciousness of the child, ${ }^{31}$ which can complicate the assessment.

\section{CONCLUSIONS}

Status epilepticus is a common neurological emergency in children. Management requires simultaneous resuscitation 
and medical stabilization, diagnosis of the underlying cause, and definitive rapid treatment. The mortality and morbidity associated with SE has decreased over the years due to a systematic approach and prompt management. Earlier the time frame for definition of status epilepticus was 30 minutes. But the use of operational definition of 5 mins., is helpful as it prevents brain damage. This was the reason for using the operational definition of 5 mins. in our study. As most of our patients presented with fever, control of fever is important in domiciliary setting. Treatment of SE needs to be started early because if they persist longer, they become more refractory to treatment and chances of complications will increase. Thus, the need for pre-hospital use of intranasal or buccal midazolam is important. Promotion of domiciliary management will thus contribute towards decreasing the burden of SE. In our study, in $4 \%$ patients, CSF study revealed antibodies against Japanese encephalitis. As it is a preventable disease, there is a need for strengthening the disease specific immunization programme especially in endemic zones for encephalitis. Neuroimaging has been a very essential aid in our study for diagnosis and management.

\section{REFERENCES}

[1] Nevander G, Ingvar M, Auer R, et al. Status epilepticus in well-oxygenated rats causes neuronal necrosis. Ann Neurol 1985;18(3):281-90.

[2] Theodore WH, Porter RJ, Albert P, et al. The secondarily generalized tonic-clonic seizure: a videotape analysis. Neurology 1994;44(8):1403-7.

[3] Murthy JM, Jayalaxmi SS, Kanikannan MA. Convulsive status epilepticus: clinical profile in a developing country. Epilepsia 2007;48(12):2217-23.

[4] Kumar M, Kumari R, Narain NP. Clinical Profile of status epilepticus (SE) in Children in a Tertiary Care Hospital in Bihar. J Clin Diagn Res 2014;8(7):PC14-7.

[5] Gulati S, Kalra V, Sridhar MR. Status epilepticus in Indian children in a tertiary care center. Indian Journal of Paediatrics 2005;72(2):105-8.

[6] Saz EU, Karapinar B, Ozcetin M, et al. Convulsive status epilepticus in children: aetiology, treatment protocol and outcome. Seizure 2011;20(2):115-8.

[7] Buchhalter J. Status epilepticus presenting as new-onset seizures in children. Epilepsy Curr 2011;11(4):112-3.

[8] Mwipopo EE, Akhatar S, Fan P, et al. Profile and clinical characterization of seizures in hospitalized children. Pan Afr Med J 2016;24:313.

[9] Singh RK, Stephens S, Berl MM, et al. Prospective study of new-onset seizures presenting as status epilepticus in childhood. Neurology 2010;74(8):636-42.

[10] Shinnar S, Pellock JM, Berg AT, et al. Short-term outcomes of children with febrile status epilepticus. Epilepsia 2001;42(1):47-53.

[11] Lacroix J, Deal C, Gauthier M, et al. Admission to a paediatric intensive care unit for status epilepticus:a 10 year experience. Crit Care Med 1994;22(5):827-32.

[12] Greiner HM, Holland K, Leach JL, et al. Nonconvulsive status epilepticus: the encephalopathic paediatric patient. Paediatrics 2012;129(3):e748-55.
[13] Yoong M, Madari R, Martinos M, et al. The role of magnetic resonance imaging in the follow-up of children with convulsive status epilepticus. Dev Med Child Neurol 2012;54(4):328-33.

[14] Lyons TW, Johnson KB, Michelson KA, et al. Yield of emergent neuroimaging in children with new-onset seizure and status epilepticus. Seizure 2016;35:4-10.

[15] Singhi P. Neurocysticercosis. Ther Adv Neurol Disord 2011;4(2):67-81.

[16] Keros S. EEG and MRI findings in children with febrile status epilepticus. February 1, 2013.

[17] Nordli DR Jr, Moshe SL, Shinnar S, et al. Acute EEG findings in children with febrile status epilepticus: results of the FEBSTAT study. Neurology 2012;79(22):2180-6.

[18] Tay SK, Hirsch LJ, Leary L, et al. Nonconvulsive status epilepticus in children: clinical and EEG characteristics. Epilepsia 2006;47(9):1504-9.

[19] Singh RK, Gaillard WD. Status epilepticus in children. Curr Neurol Neurosci Rep 2009;9(2):137-44.

[20] Riviello JJ Jr, Ashwal S, Hirtz D, et al. Practice parameter: diagnostic assessment of the child with status epilepticus (an evidence-based review): report of the Quality Standards Subcommittee of the American Academy of Neurology and the Practice Committee of the Child Neurology Society. Neurology 2006;67(9):1542-50.

[21] Bhattacharjee S, Biswas P, Mondal T. Clinical profile and follow up of 51 paediatric neurocysticercosis cases: a study from eastern India. Ann Indian Acad Neurol 2013;16(4):549-55.

[22] Sadarangani M, Seaton C, Scott JA, et al. Incidence and outcome of convulsive status epilepticus in Kenyan children: a cohort study. Lancet Neurol 2008;7(2):14550.

[23] Bleck TP. Less common etiologies of status epilepticus. Epilepsy Curr 2010;10(2):31-3.

[24] Smith DM, McGinnis EL, Walleigh DJ, et al. Management of status epilepticus in children. J Clin Med 2016;5(4):pii: E47.

[25] Misra UK, Kalita J, Patel R. Sodium valproate vs phenytoin in status epilepticus: a pilot study. Neurology 2006;67(2):340-2.

[26] Misra UK, Kalita J, Maurya PK. Levetiracetam versus lorazepam in status epilepticus: a randomized, open labeled pilot study. J Neurol 2012;259(4):645-8.

[27] Silbergleit R, Durkalski V, Lowenstein D, et al. Intramuscular versus intravenous therapy for prehospital status epilepticus. N Engl J Med 2012;366(7):591-600.

[28] Chamberlain JM, Okada P, Holsti M, et al. Lorazepam vs diazepam for paediatric status epilepticus: a randomized clinical trial. JAMA 2014;311(16):1652-60.

[29] Appleton R, Sweeney A, Choonara I, et al. Lorazepam versus diazepam in the acute treatment of epileptic seizures and status epilepticus. Dev Med Child Neurol 1995;37(8):682-8.

[30] Treiman DM, Meyers PD, Walton NY, et al. A comparison of four treatments four generalized convulsive status epilepticus. Veterans Affairs status epilepticus Cooperative Study Group. N Engl J Med 1998;339(12):792-8.

[31] Shinnar S, Berg AT, Moshe SL, et al. How long do newonset seizures in children last? Ann Neurol 2001;49(5):659-64 